\title{
In Vivo Nerve-Macrophage Interactions Following Peripheral Nerve Injury
}

\author{
Allison F. Rosenberg, Marc A. Wolman, Clara Franzini-Armstrong, and Michael Granato \\ Department of Cell and Developmental Biology, University of Pennsylvania School of Medicine, Philadelphia, Pennsylvania 19104-6058
}

In vertebrates, the peripheral nervous system has retained its regenerative capacity, enabling severed axons to reconnect with their original synaptic targets. While it is well documented that a favorable environment is critical for nerve regeneration, the complex cellular interactions between injured nerves with cells in their environment, as well as the functional significance of these interactions, have not been determined in vivo and in real time. Here we provide the first minute-by-minute account of cellular interactions between laser transected motor nerves and macrophages in live intact zebrafish. We show that macrophages arrive at the lesion site long before axon fragmentation, much earlier than previously thought. Moreover, we find that axon fragmentation triggers macrophage invasion into the nerve to engulf axonal debris, and that delaying nerve fragmentation in a Wld ${ }^{s}$ model does not alter macrophage recruitment but induces a previously unknown 'nerve scanning' behavior, suggesting that macrophage recruitment and subsequent nerve invasion are controlled by separate mechanisms. Finally, we demonstrate that macrophage recruitment, thought to be dependent on Schwann cell-derived signals, occurs independently of Schwann cells. Thus, live cell imaging defines novel cellular and functional interactions between injured nerves and immune cells.

\section{Introduction}

In response to injury, axons of both the CNS and the peripheral nervous system (PNS) undergo a stereotyped and genetically regulated form of self-destruction known as Wallerian degeneration (Waller, 1849). Key to this process is the $\mathrm{Wld}^{\mathrm{s}}$ protein, originally identified in C57BL/Ola mice, which delays axonal fragmentation through a cell autonomous mechanism (Lunn et al., 1989; Perry et al., 1990; Coleman et al., 1998; Conforti et al., 2000; Raff et al., 2002). While the axon autonomous mechanisms of this self-destruction program have been studied extensively, the cellular and molecular interactions between injured axons and nonneuronal cells such as glial and immune cells are less well characterized. In the periphery, Schwann cells and macrophages remove the cellular and membranous debris of the fragmented nerve, thereby generating an extracellular milieu conducive to axonal regeneration (Holtzman and Novikoff, 1965; for review, see O'Daly and Imaeda, 1967; Stoll et al., 1989b; Hirata et al., 1999; Hirata and Kawabuchi, 2002; Vargas and Barres, 2007).

In addition to their phagocytic role, Schwann cells are thought to recruit immune cells to the lesion site (Banner and Patterson, 1994; Subang and Richardson, 1999; Shamash et al., 2002; Tofaris et al., 2002), and macrophage infiltration and rapid debris removal are considered key prerequisites for nerve regeneration (for review, see

\footnotetext{
Received 0ct. 12, 2011; revised Jan. 18, 2012; accepted Jan. 25, 2012.

Author contributions: A.F.R., M.A.W., C.F.-A., and M.G. designed research; A.F.R., M.A.W., and C.F.-A. performed research; A.F.R., M.A.W., C.F.-A., and M.G. analyzed data; A.F.R. and M.G. wrote the paper.

This work was supported by grants to A.F.R. (T32-GM007229 and F31 NS071722-01) and to M.G. (NIH R21-NS070032, NIH HD-37975, and Muscular Dystrophy Association-131174). Thanks to D. Gilmour, F. Peri, and J. Milbrandt for providing constructs and fish lines. Thanks to Jonathan Raper and lab members for critical comments.

The authors declare no competing financial interests.

Correspondence should be addressed to Michael Granato at the above address. E-mail: granatom@mail.med.upenn.edu.

DOI:10.1523/JNEUROSCI.5225-11.2012

Copyright $\odot 2012$ the authors $\quad 0270-6474 / 12 / 323898-12 \$ 15.00 / 0$
}

Perry and Brown, 1992). For example, Wld ${ }^{\text {s }}$ overexpression in sensory axons reduces macrophage recruitment and delays functional regeneration, suggesting that the processes of axonal degeneration and regeneration are intricately interconnected (Bisby and Chen, 1990; Brown et al., 1992; Chen and Bisby, 1993a,b). Yet despite their importance for nerve degeneration and regeneration, the cellular interactions between injured nerves and macrophages have not been determined in vivo and in real time.

Here, we examine the cellular interactions between motor nerves and macrophages following complete nerve transection. We show that as in mammals, myelinated zebrafish peripheral motor nerves undergo Wallerian degeneration, followed by functional regeneration, and that motor axons are sensitive to $\mathrm{Wld}^{\mathrm{s}}$ expression. We provide the first minute-by-minute account of the destruction speed and synchrony of individual motor axons in a live intact vertebrate animal. Moreover, using overexpression and loss-of function approaches we characterize macrophage recruitment to injured nerves and demonstrate that macrophage recruitment and function occurs independently of Schwann cells. Finally, we uncover a previously uncharacterized plasticity of macrophage behavior as they interact with injured nerves.

\section{Materials and Methods}

Zebrafish genetics and transgenes. All transgenic lines are maintained in the Tubingen or Tupfel longfin (TL) genetic background and raised as described previously (Mullins et al., 1994). For the majority of the experiments described, the $\operatorname{Tg}(m n x 1: G F P)^{m l 2}$ (Flanagan-Steet et al., 2005) (ZFIN ID: ZDB-ALT-051025-4) and the Tg(Xla.Tubb:DsRed) ${ }^{z f 148}$ (Peri and Nüsslein-Volhard, 2008) (ZFIN ID: ZDB-ALT-081027-2) lines were used to label spinal motor nerves, and the $\mathrm{Tg}$ (spi1:Gal4,UAS:EGFP)zf149 (ZFIN ID: ZDB-ALT-081027-3) transgene to label leukocytes, including macrophages (Peri and Nüsslein-Volhard, 2008). Sox $10^{-1-}$ (colorless) mutants (Kelsh et al., 1996; Dutton et al., 2001) were used in Figure 7. The $\operatorname{Tg}\left(m n x 1: W l d^{s}-G F P\right)^{p 160}$ line was generated by microinjection of $m n x 1: W l d^{s}$-GFP plasmid DNA as previously described (Thermes et al., 

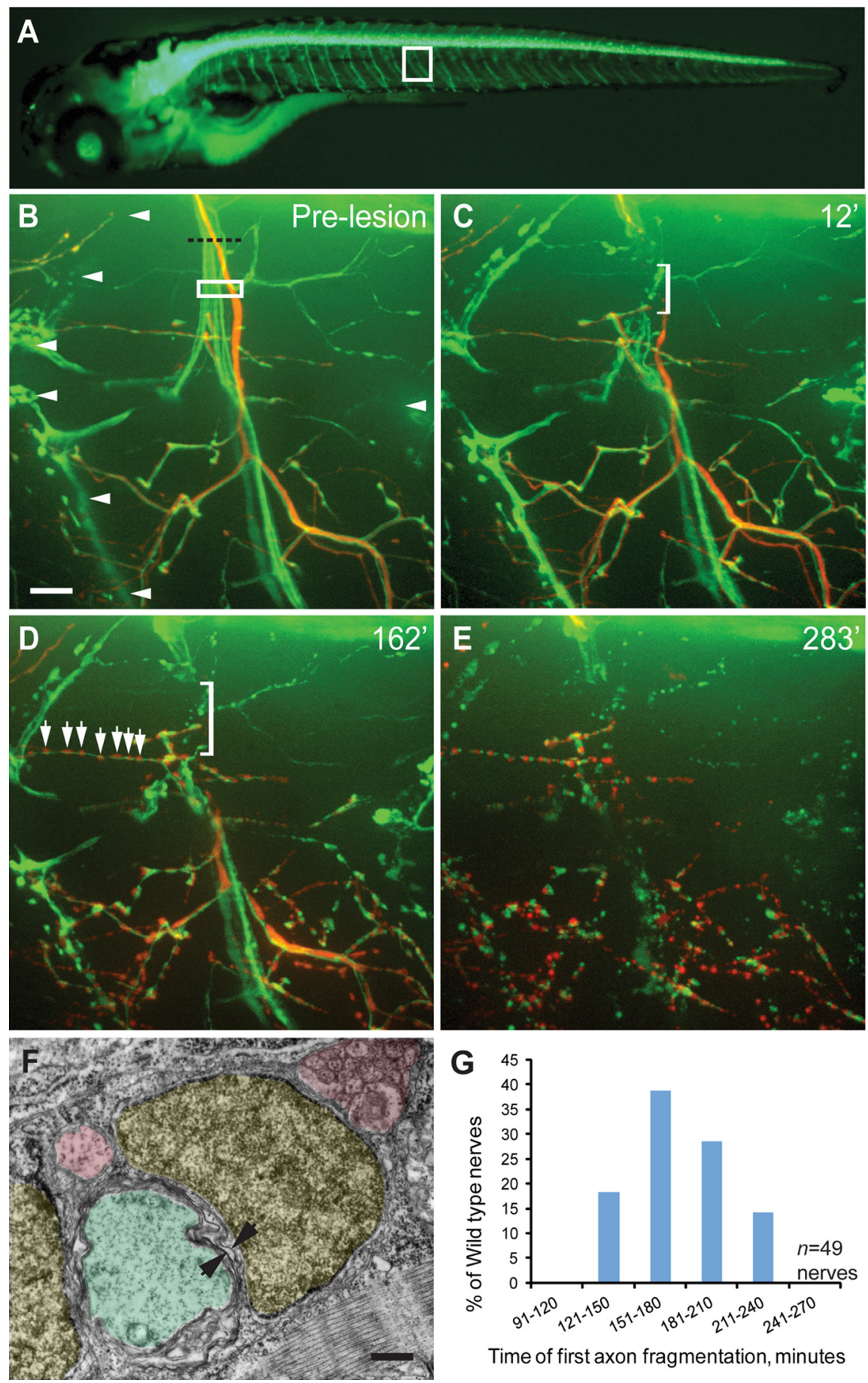

Time of first axon fragmentation, minutes

Figure 1. Nerve degeneration in zebrafish. $A, A 5 \mathrm{dpf} \operatorname{Tg}(m n \times 1$ :GFP) larva expressing GFP in spinal motor neurons and their axons. White box outlines a single motor nerve. $\boldsymbol{B}$, Spinal motor nerve magnified from white box in $\boldsymbol{A}$ with single cell $m n x 1$ :dsRed labeling. White rectangle indicates area of laser axotomy; arrowheads point to the nerve extending along the hemisegment boundary. $(-E$, Following transection, a gap forms in the nerve (bracket). $C, D$, Axon fascicles retract both proximally and distally from the lesion site (bracket) until fragmentation starts ( $\boldsymbol{D}$, arrows). Eventually, the entire distal nerve fragments, and the debris is gradually cleared $(\boldsymbol{E})$. Scale bar, $10 \mu \mathrm{m}$. $\boldsymbol{F}$, Electron micrograph of a cross section through a trunk motor nerve at the depth of the dashed line in $\boldsymbol{B}$. Schwann cells are shaded yellow, small-diameter axons are shaded pink, and large-diameter axons are shaded green. Arrows point to myelin sheath. Scale bar, $500 \mathrm{~nm}$. G, Quantification of nerve fragmentation onset from 49 nerves in 18 animals.

2002). Zebrafish of either sex were used, and all zebrafish work was conducted in accordance with Institutional Animal Care and Use Committee regulatory standards.

Stochastic cell labeling. Axons were stochastically labeled by microinjection of $33 \mathrm{pg}$ of $m n x 1: d s R e d$ DNA at the 1 cell stage as previously described (Thermes et al., 2002). The dsRed fluorophore will be strongly expressed by 24 hours postfertilization, concomitantly with the expression of GFP in the transgenic line $\operatorname{Tg}(m n x 1: G F P)^{m l 2}$

Plasmid construction. Standard molecular biology methods were used to generate the $m n x 1: W l d^{s}$-GFP plasmid with Isce-I meganuclease sites for DNA injection. The $\mathrm{Wld}^{\mathrm{s}}$ gene was a kind gift from Dr. J. Milbrandt (Washington University School of Medicine, St. Louis, $\mathrm{MO}$ ), and was cloned from the pcDNA3 vector using the flanking BamHI sites into the pBluescript vector. To make a C-terminally tagged Wld ${ }^{\mathrm{s}}$ construct the Wld ${ }^{\mathrm{s}} \mathrm{C}$-terminal end was mutagenized before the stop codon to engineer in a NheI site (Stratagene Quikchange II XL site-directed mutagenesis kit). eGFP was then cloned into the NheI site. A EcoRI/XbaI digestion was used to clone Wld ${ }^{\mathrm{s}}$-eGFP into pCS2+, and then, using the Gateway system (Hartley et al., 2000), Wld ${ }^{\mathrm{s}}$-eGFP was moved into the pIsce-I expression plasmid downstream of the $\mathrm{mnxl}$ promoter in between the SpeI and XbaI sites.

The following Site-Directed Mutagenesis Primers were used to engineer in a NheI site before the Wld ${ }^{\text {s }}$ stop codon for insertion of eGFP: 5'ACCACTTCCACTTTGGCTAGCTCATCAC CATCACC3' (forward), 5'GGTGATGGTGAT GAGCTAGCCAAAGTGGAATGGT3' (reverse).

Nerve transection. Nerve injury was performed using a MicroPoint Computer-Controlled ablation system (Andor Technology) consisting of a nitrogen-pumped dye laser (wavelength $435 \mathrm{~nm}$ ) controlled by MetaMorph version 7.7 or by Slidebook version 5.0. Ablation laser settings on either software package ranged from power 55 to 72 depending on the age of the cumerin dye. One to four motor nerves per larva in hemisegments 10-16 were transected in all experiments (see Figs. 1-8), except in Figure 4, $\mathrm{H}-\mathrm{O}$ (see below), where 28 motor nerves (hemisegments 5-33) were transected per larva. To transect nerves a thin rectangular ROI was drawn digitally in either Slidebook or Andor Technology MicroPoint over the image of the nerve, $\sim 20 \mu \mathrm{m}$ from the spinal cord exit point, and the nerve was laser pulsed precisely within that ROI in $\sim 20 \mathrm{~s}$ intervals until all axons in the nerve appeared transected, whereby axonal fluorescence did not refill the ROI in $>10 \mathrm{~s}$.

Live imaging. Larvae at 5 days postfertilization (dpf) were mounted in MatTek glass bottom culture dishes in $1.5 \%$ low melt SeaPlaque agarose prepared with Ringer's plus Tricaine $(0.016 \%$ Tricaine). Images were acquired on an Olympus IX 71 or 81 microscope equipped with a Yokogawa CSU 10 scan head combined with a Hamamatsu EMCCD camera (model C9100-13). Acquisition and hardware were controlled by MetaMorph version 7.7 or Slidebook version 5.0, respectively. Diode lasers for excitation $(488 \mathrm{~nm}$ for GFP and $561 \mathrm{~nm}$ for dsRed) were housed in a Spectral Applied Research launch. Image stacks for time lapse movies were acquired every $5-10 \mathrm{~min}$, typically spanning $60-75 \mu \mathrm{m}$ at 1 $\mu \mathrm{m}$ intervals, with an Olympus $60 \times, 1.2 \mathrm{NA}$ (numerical aperture) UPlanSApo water-immersion objective. The gain for all images captured was set at 191, resolution was $512 \times 512$ pixel resolution, and image 
capture time for nerves was between 150 and $300 \mathrm{~ms}$ (50-100 ms for cell bodies). For imaging over $2 \mathrm{~h}$, Immersol was used instead of water. GFP emission filter: 525/50, lot no. 119342, mCherry emission filter: 630/75, lot no. 200406. For regeneration experiments, larvae were removed from agarose and Tricaine following transection and left to recover in clean E3 in individual Petri dishes. Larvae were remounted as above for each imaging session at 24 or $48 \mathrm{~h}$ post-lesion.

Image processing. Image stacks were compressed into maximum intensity projections (MIPs) in their respective acquisition software package. MIPs were exported and gamma adjusted to 0.5 in ImageJ for increased visibility, color assigned by acquisition wavelength, and analyzed. Brightness, contrast, and color levels were adjusted for maximal visibility in Adobe Photoshop CS4.

Electron microscopy. Embryos at $5 \mathrm{dpf}$ were fixed in $6 \%$ glutaraldehyde in either $0.1 \mathrm{M}$ cacodylate or phosphate buffer $\mathrm{pH}$ 7.2-7.4 for at least $1 \mathrm{~h}$ at room temperature, and used immediately or stored for up to several days at $4^{\circ} \mathrm{C}$ in the fixative. Head, yolk sac, yolk extension and most of the tail fin were removed within the first minutes of fixation to allow better penetration of the fixative. Tails were postfixed in $2 \% \mathrm{OsO} 4$ in the same buffer, en bloc stained with saturated aqueous uranyl acetate for $2 \mathrm{~h}$, and embedded in Epon 812. Sections were cut in a Leica Ultracut R ultramicrotome using a Diatome diamond knife (CH-2501), stained in lead citrate solution, and examined in a Phillips 410 electron microscope (Philips Electron Optics) equipped with a Hamamatsu C4742-95 digital imaging system (Advanced Microscopy Techniques).

Behavioral assays, video recording, and behavioral analysis. Acoustic startle responses were elicited, recorded, and measured as previously described (Burgess et al., 2009), with the following modifications. To record acoustic startle responses, high-speed video images were recorded using a Motion Pro camera (Redlake) at 1000 frames per second, and with $512 \times 512$ pixel resolution, using a $50 \mathrm{~mm}$ macro lens. Behavioral analysis was performed with the FLOTE software package to determine initiation and the kinematic properties of acoustic startle responses (Burgess and Granato, 2007; Burgess et al., 2009). Student's $t$ test was used to calculate $p$-values. Acoustic startle stimuli were provided by a small vibrational excitor (Bruel and Kjaer), with $3 \mathrm{~ms}$ duration, $1000 \mathrm{~Hz}$ waveforms, of $\sim 150 \mathrm{~m} / \mathrm{s}^{2}$. Stimulus intensity was calculated by measuring the approximate displacement of the testing arena due to vibration. To evaluate acoustic startle behavior images were recorded $30 \mathrm{~ms}$ before and $90 \mathrm{~ms}$ following the delivery of the acoustic stimulus. All acoustic startle experiments were performed in a $4 \times 4$ testing arena so larvae could be tracked and analyzed individually. The $4 \times 4$ testing grids were laser-cut from acrylic by Pololu Corporation and then glued to a circular acrylic base plate $(56 \mathrm{~mm}$ diameter, $1.5 \mathrm{~mm}$ thick; Pololu Corporation) with thin acrylic cement (Weld-On \#3, IPS Corporation). The base plate was affixed to the inside of a $6 \mathrm{~cm}$ Petri dish lid with acrylic cement (Weld-On \#16, IPS Corporation). The Petri dish lid was then attached to a metal ring with modeling clay, and the metal ring was connected to the vibrational excitor by a titanium rod (Burgess and Granato, 2007; Burgess et al., 2009). For image capture purposes, a 96 bulb infrared LED array (IR100 Illuminator removed from housing, YYtrade Inc.) was positioned below the testing arena. A three mm-thick sheet of white acrylic, positioned $\sim 3 \mathrm{~cm}$ below the testing arena, diffused the infrared light. A white LED bulb (PAR38 LED light, LEDlight.com) was po-

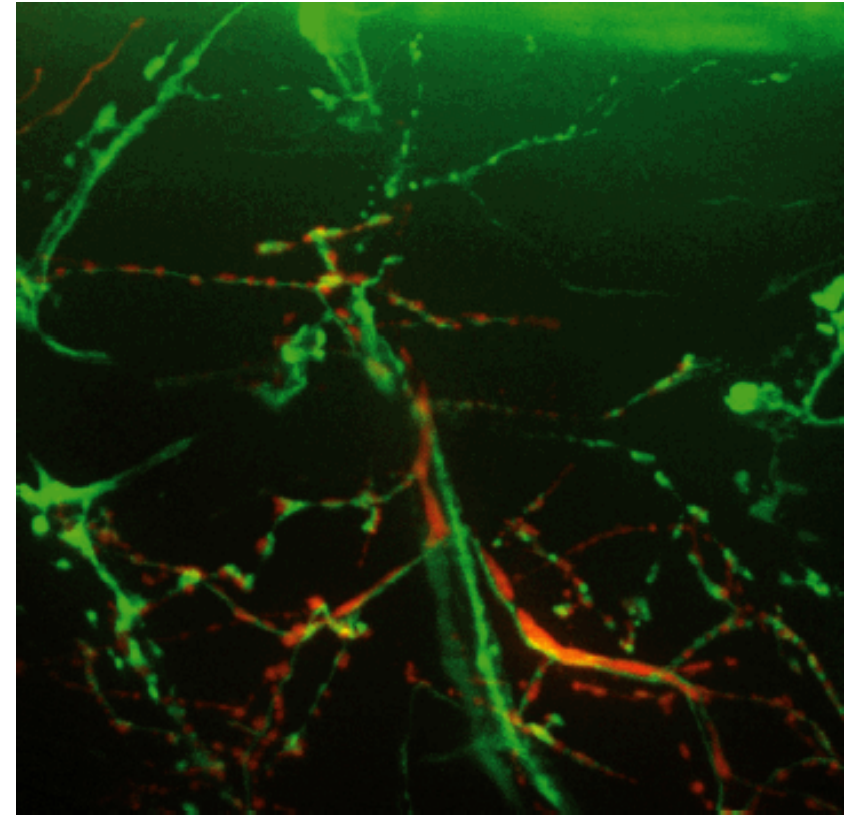

Movie 1. Time lapse imaging of transected motor nerve in a $5 \mathrm{dpf} z$ zebrafish undergoing Wallerian degeneration. Transgenic larva expresses cytoplasmic GFPin all spinal motorneurons ( $\operatorname{Tg}(m n x 1: G F P))$. White rectangle on nerve indicates area to be transected by laser. Frames are every $5 \mathrm{~min}$ for $\sim 7 \mathrm{~h}$.
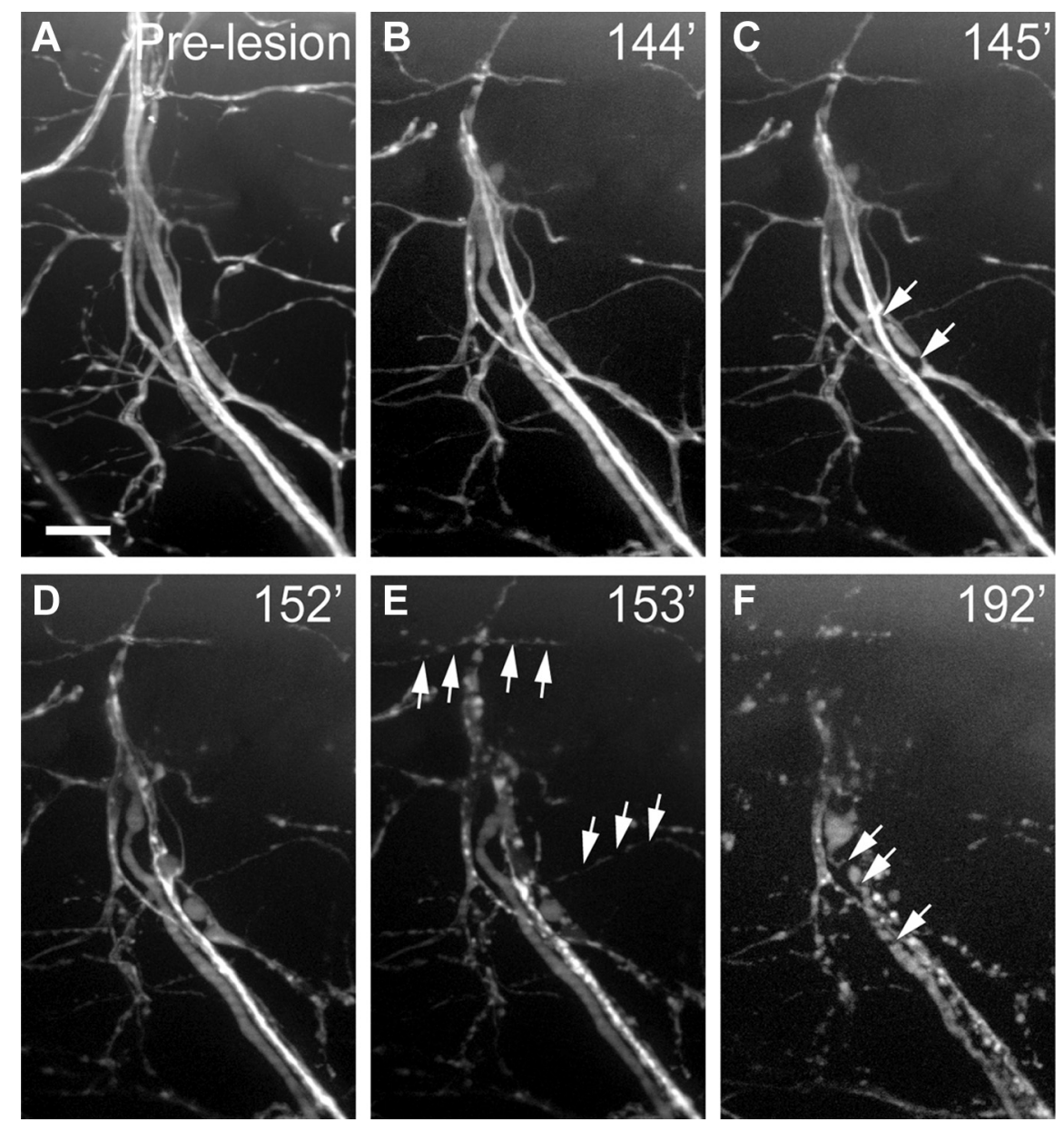

Figure 2. Individual axons degenerate independently, with sub-minute timing, and succession of fragmentation is independent of axon diameter. $A$, Pre-lesion image of motor nerve in $5 \mathrm{dpf} \operatorname{Tg}(m n x 1: G F P)$ larva. $\boldsymbol{B}, \boldsymbol{C}$, All axons are intact the minute before the first axon, of large diameter, begins to fragment ( $\boldsymbol{C}$, arrows). $\boldsymbol{D}-\boldsymbol{F}$, Individual axons continue to fragment within the nerve $(\boldsymbol{D})$ and after $1 \mathrm{~min}$, several small-diameter axons fragment ( $\boldsymbol{E}$, arrows), followed later by another large-diameter axon ( $\boldsymbol{F}$, arrows). Scale bar, $10 \mu \mathrm{m}$. 

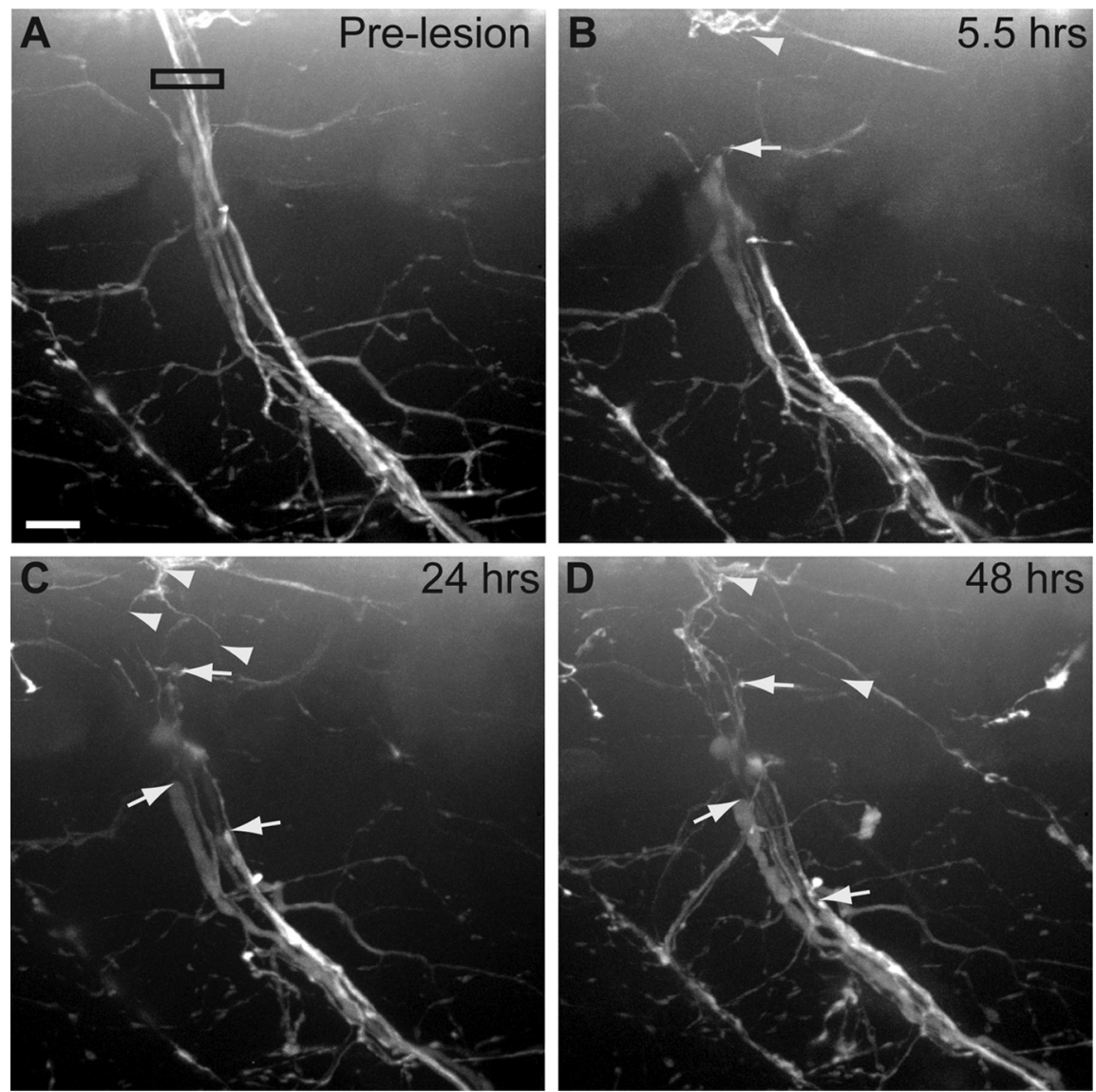

Figure 3. Axonal expression of Wld ${ }^{5}$ delays Wallerian degeneration. $A$, Pre-lesion image of a $T g\left(m n x 1: W I d^{5}-G F P\right)$; $T g$ (mnx1:GFP)-expressing nerve. Black box indicates area of laser axotomy. $\boldsymbol{B}$, Although completely transected, the dista portion of $\operatorname{Tg}\left(m n \times 1: W I d^{5}-G F P\right) ; \operatorname{Tg}(m n \times 1: G F P)$-expressing nerve remains intact. Arrowhead indicates proximal nerve stump; arrows indicate most proximal end of distal nerve fascicles. C, D, Distal nerve remains intact $24 \mathrm{hpt}(\boldsymbol{C})$ and $48 \mathrm{hpt}(\boldsymbol{D})$, while axons continue to retract from lesion site (arrows). Some axons from the proximal stump have begun to regrow (arrowheads). Scale bar, $10 \mu \mathrm{m}$.

sitioned above the testing arena to illuminate the testing arena with white light.

\section{Results}

Zebrafish spinal motor nerves as a model for injury-induced Wallerian Degeneration

To monitor the events during nerve degeneration in real time we imaged zebrafish spinal motor nerves between 5 and $7 \mathrm{dpf}$ following complete nerve transection. We used a pumped dye laser (MicroPoint, Andor Technology) to transect individual, $\operatorname{Tg}(m n x 1$ : GFP)-positive motor nerves within the first $\sim 20 \mu \mathrm{m}$ of their peripheral trajectory (Fig. 1A,B; Flanagan-Steet et al., 2005). Zebrafish motor nerves consist of $\sim 70$ motor axons (Myers, 1985; Westerfield et al., 1986), of which the large-diameter axons are myelinated by Schwann cells, while the small-diameter axons exhibit little or no myelination (Fig. $1 F$ ). This is roughly equivalent to the degree of myelination seen within the first postnatal week in mouse and rat (Peters and Muir, 1959; Schlaepfer and Myers, 1973; Hahn et al., 1987; for review, see Garbay et al., 2000). To visualize individual axons in the context of the entire nerve we stochastically labeled individual motor neurons using $m n x 1$ :dsRed. Stochastic labeling results in individual cells that retain and express the injected DNA construct, surrounded by cells which do not retain the DNA and hence do not express the construct (Downes et al., 2002). Individual motor axons form primary, secondary and tertiary branches that synapse with the underlying muscle fibers, and also form myotendinous junctions along hemisegment boundaries (Fig. 1B; Myers et al., 1986; Westerfield et al., 1986; Zhang et al., 2004). Time-lapse analysis of uninjured motor nerves revealed occasional and short-lived ( $<20 \mathrm{~min}$ ) filopodial extensions and retractions of $<11 \mu \mathrm{m}$ (data not shown). Importantly, the overall anatomy and branching pattern of individual axons and nerves was stable over several hours and even days, characteristic for mature peripheral nerves.

We first documented the morphological changes following complete nerve transection (Fig. 1; see also Movie 1). Immediately following lesion the proximal and distal nerve fascicles sprang apart, resulting in a gap at the lesion site (Fig. 1C). Over the next 120-240 min the proximal and distal nerve stumps continued to retract until the distal portion of the nerve began to fragment rapidly (Fig. $1 D$, quantified in $G$ ). Interestingly, once initiated, fragmentation occurred along the entire length of individual axons within minutes (Figs. 1D, 2A-F). Individual axons within the transected nerve initiated fragmentation at different times, independent of axon diameter or myelination (Fig. 2C-F). Eventually, the entire nerve fragmented (Fig. $1 E$ ), and over the next $24 \mathrm{~h}$ axonal debris was gradually removed (see Fig. $4 B, C$ ). Analysis of 49 transected nerves in 18 animals revealed that spinal motor nerve degeneration occurs with stereotyped and quantifiable parameters. As shown in Figure $1 G$, axonal fragmentation is first detected between 121 and $240 \mathrm{~min}$, with the majority of nerves starting to fragment between 151 and $210 \mathrm{~min}$ post-transection.

In all species tested, expression of the Wallerian Degeneration Slow protein $\left(\mathrm{Wld}^{\mathrm{s}}\right.$ ) significantly delays the onset of axon fragmentation through an axon-autonomous mechanism, consistent with an evolutionarily conserved, Wld ${ }^{\text {s }}$ sensitive axonal destruction program (Martin et al., 2010; Lunn et al., 1989; Wang et al., 2001; Raff et al., 2002; Araki et al., 2004; Adalbert et al., 2005; Hoopfer et al., 2006; MacDonald et al., 2006). Transient expression of Wld ${ }^{\mathrm{s}}$ in individual zebrafish sensory and CNS axons provides neuroprotection (Feng et al., 2010; Martin et al., 2010), however, neither transient nor transgenic Wld ${ }^{\mathrm{s}}$ models for zebrafish motor neurons have been reported. Therefore, we generated several stable transgenic lines expressing high levels of GFP tagged Wld ${ }^{\mathrm{s}}$ under the control of the motor neuron-specific $m n x 1$ promoter. Motor nerves in the $T g\left(m n x 1: W l d^{s}-G F P\right)^{p 160}$ line that stably express Wld ${ }^{\mathrm{s}}$-GFP are morphologically indistinguishable from those in wild-type animals (Fig. 3A). Following laser-mediated transection, Wld ${ }^{\mathrm{s}}$-GFP-expressing nerves do not degenerate and instead remain intact for up to $8 \mathrm{~d}$ ( $n=25$ nerves; Fig. $3 B-D$ compared with Fig. $1 D, E)$. Thus, stable transgenic expression of Wld ${ }^{s}$ in zebrafish motor neurons efficiently delays injury-induced Wallerian degeneration. Combined, these data demonstrate that following transection zebrafish spinal motor 

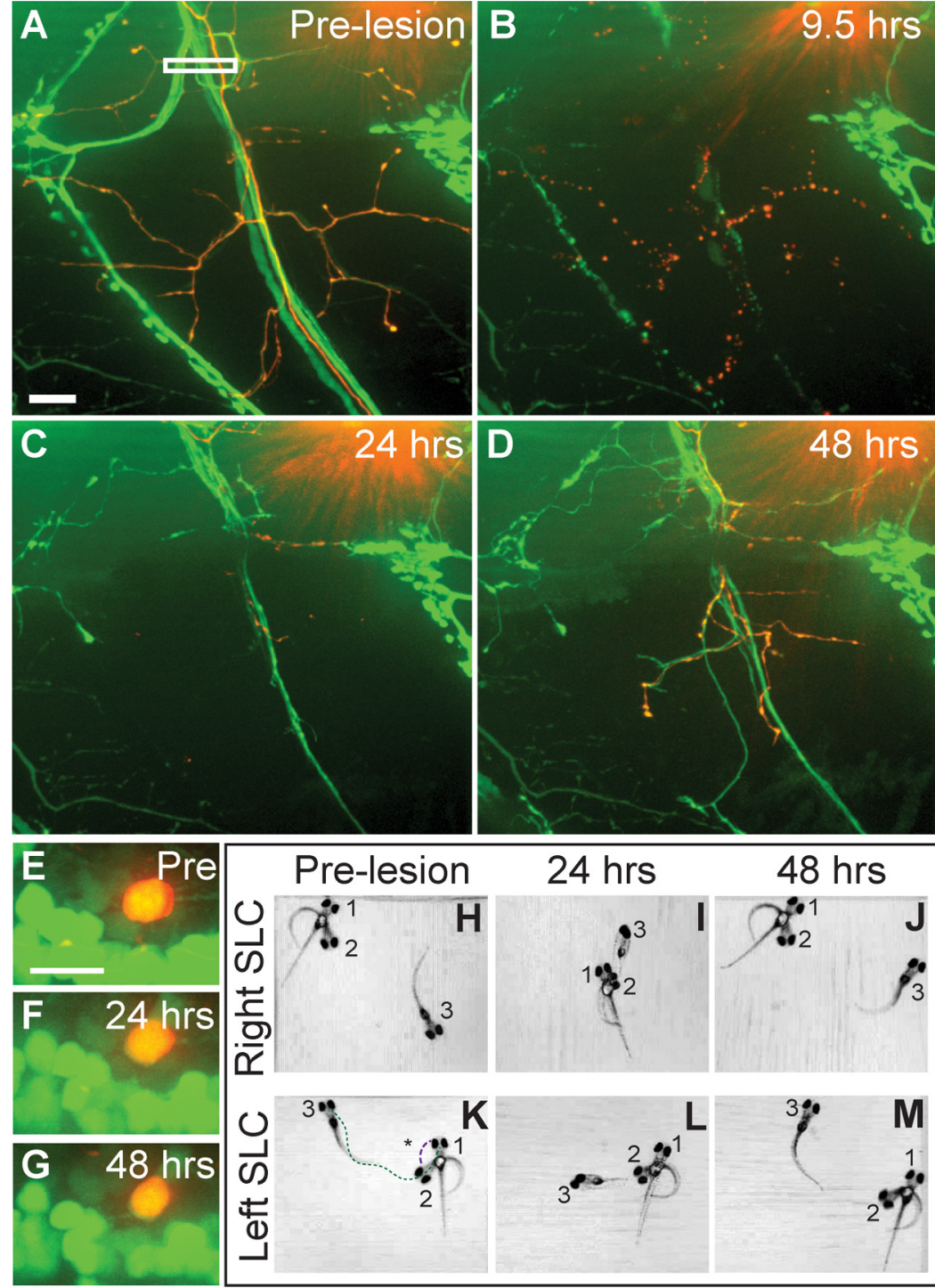

$24 \mathrm{hrs}$
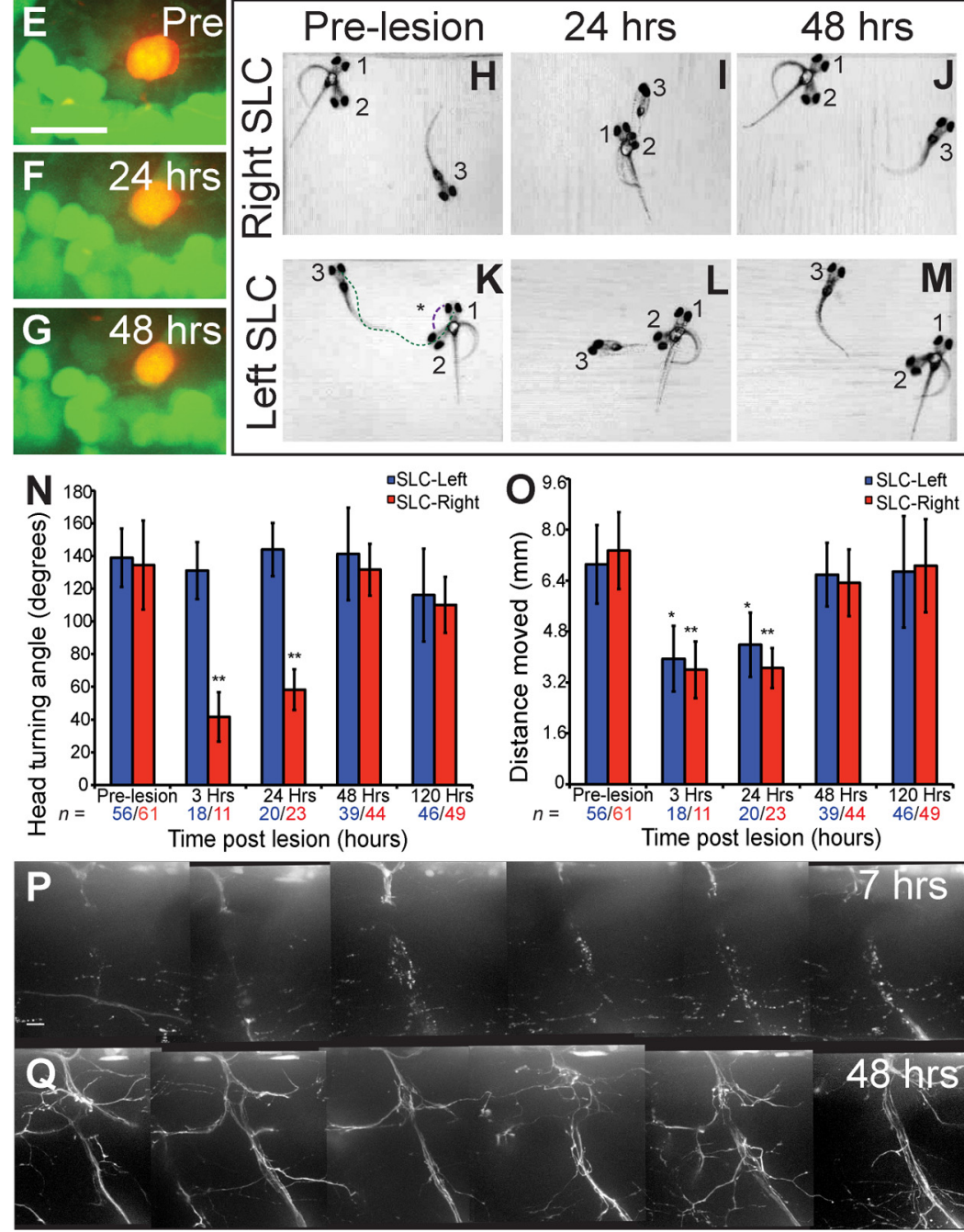

Figure 4. Functional regeneration of transected motor nerves. $\boldsymbol{A}$, Pre-lesion nerve in $\operatorname{Tg}(m n \times 1: G F P)$ with $m n \times 1$ :dsRed-colabeled axons. White box indicates area of laser axotomy. $\boldsymbol{B}$, At $9.5 \mathrm{hpt}$ nerve has completely fragmented. $\boldsymbol{C}$, At $24 \mathrm{hpt} \mathrm{GFP}^{+}$and dsRed $^{+}$ axons degenerate through a Wld ${ }^{\mathrm{s}}$ sensitive process with morphological hallmarks characteristic of Wallerian degeneration.

\section{Functional recovery of transected motor nerves}

In vertebrates, peripheral axons have retained their capacity for regrowth and frequently achieve functional regeneration. Regrowth of individual sensory and CNS axons has been documented in larval zebrafish (van Raamsdonk et al., 1998; Bhatt et al., 2004; O'Brien et al., 2009; Reimer et al., 2009; Martin et al., 2010; Wyatt et al., 2010), yet a time course of functional recovery of transected peripheral nerves has not yet been reported. $\operatorname{Tg}(m n x 1: G F P)$ nerves containing a small number of $m n x 1: d s R e d$-positive axons (1-5 axons) were transected as before and repeatedly imaged over a time course of up to $5 \mathrm{~d}$ (Fig. $4 A-D)$. At 9.5 hours post-transection (hpt) the entire nerve portion distal to the transection site had fragmented, leaving behind only axonal debris (Fig. $4 B$ ). Importantly, the somata of axotomized mnx1:dsRedpositive motor neurons survived (Fig. $4 E-G, n=19$ of 19 neurons), and within 24 hpt these dsRed-positive motor neurons reextended axons along with GFP-positive axons past the lesion site into the ventral myotome (Fig. $4 C, n=29$ of 52 nerves). Regenerating axons regrew through the center of the hemisegment, following the precise trajectory originally established during development (Westerfield et al., 1986). Within 48 hpt, GFP and dsRed-positive axons extended and reestablished complex branches throughout the ventral myotome and along hemisegment boundaries (Fig. $4 D, n=23$ of 37 nerves).

axons have regrown into the ventral myotome and the hemisegment boundaries. $\boldsymbol{D}$, At $48 \mathrm{hpt}$ axons have extended throughout the ventral myotome and branched. $\boldsymbol{E}-\boldsymbol{G}$, DsRed $^{+}$and $\mathrm{GFP}^{+}$somas remain intact 24 and $48 \mathrm{~h}$ after axotomy. Scale bar, $10 \mu \mathrm{m}$. $\boldsymbol{H}-\boldsymbol{M}$, Composites from high speed movies (1000 frames/s) document startle performance (SLC), before acoustic stimulation (position 1), at maximum (-bending angle (position 2), and $90 \mathrm{~ms}$ after stimulation (position 3). Asterisk indicates initial head turning angle, quantified in $\boldsymbol{N}$, and green dotted line indicates swimming distance, quantified in $\mathbf{O} . \mathbf{N}, \mathbf{0}$, Quantification of SLC performance, measuring the head angle $(\boldsymbol{N})$ and swim distance $(\boldsymbol{O})$, comparing turns to the left (control side, blue), and right (experimental side, red). $n=$ number of rightward or leftward startle responses analyzed. ${ }^{*} p<0.001$ vs SLC-Leftward Pre-lesion, ${ }^{* *} p<0.001$ vs SLC-Rightward Pre-lesion. $\boldsymbol{P}$, At 7 hpt the transected nerves in hemisegments $5-10$ have fragmented distal to the lesion. Q, At $48 \mathrm{hpt}$ axons in hemisegments 5-10 have reextended through the ventral myotome and branched. Scale bar, $10 \mu \mathrm{m}$. 

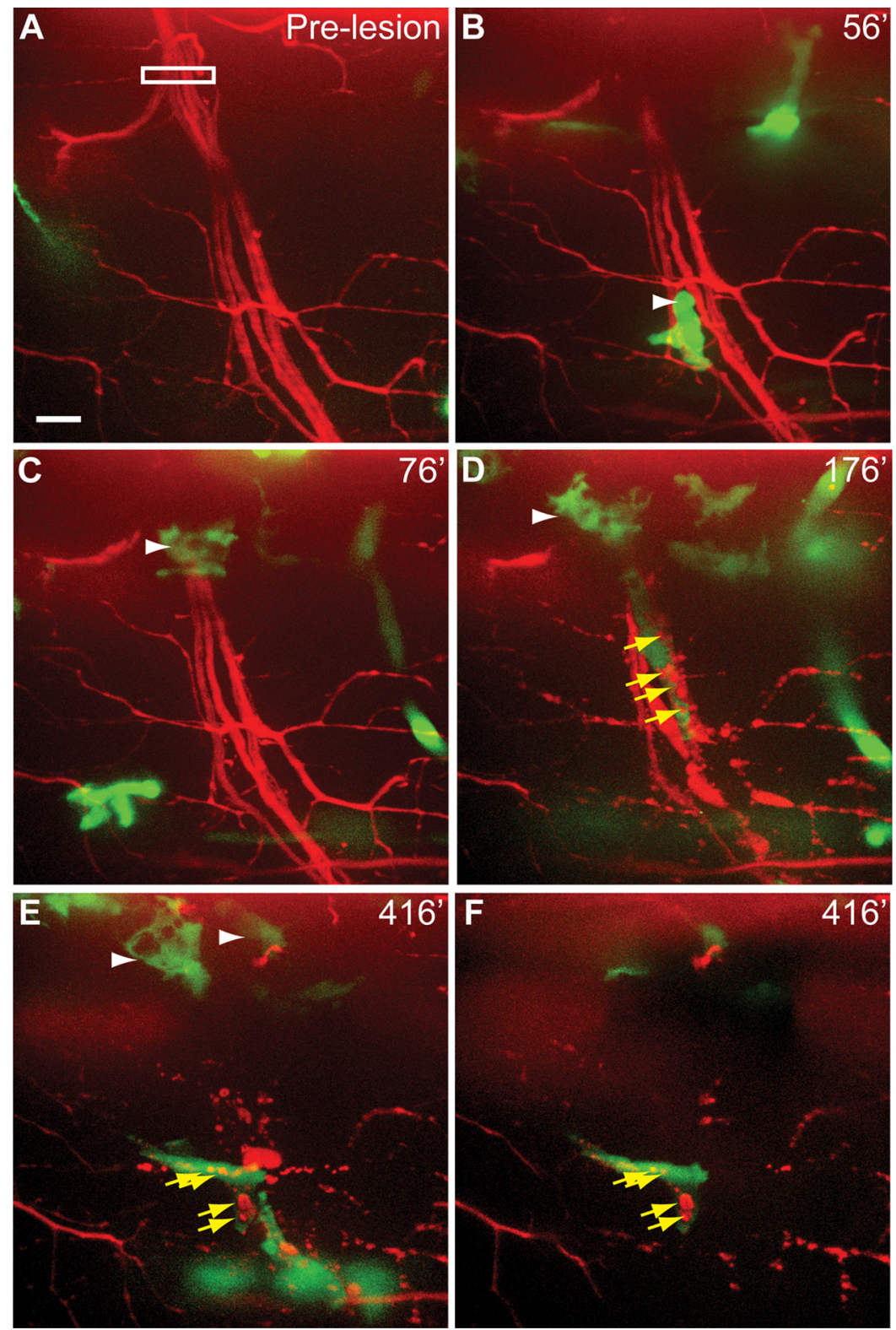

Figure 5. Recruitment and function of macrophages following nerve injury. A, Pre-lesion image in $T g$ (X1a.Tubb:DsRed) Tg(spi1-Gal4,UAS-GFP) larva. White box indicates area of laser axotomy. B, Macrophages (arrowhead) arrive and contact the lesioned distal nerve. $\boldsymbol{C}$, Additional macrophages (arrowhead) are recruited to the lesion site. $\boldsymbol{D}$, Upon onset of nerve fragmentation, macrophages phagocytose distal axon debris (yellow arrows). $\boldsymbol{E}$, Hours after lesioning, macrophages remain at both the lesion site (arrowheads) and the distal nerve where they phagocytose debris (yellow arrows). $\boldsymbol{F}$, Projection of eight focal $z$-planes from $\boldsymbol{E}$, totaling $8 \mu \mathrm{m}$ deep, show red axonal debris within green macrophages. Scale bar, $10 \mu \mathrm{m}$.

We next asked whether these regrown axons restore functionality to their muscle targets. To address this we used a well established and quantifiable behavioral assay, the startle response (Kimmel et al., 1974; Liu and Fetcho, 1999; Burgess and Granato, 2007). The startle response is characterized by a short latency C-start (termed SLC), followed by a short swimming episode, and its performance critically depends on the simultaneous and unilateral activation of trunk muscle by spinal motor nerves (Fig. 3H; Eaton and Hackett, 1984; Liu and Westerfield, 1988; Liu and Fetcho, 1999). Before nerve transections, $\operatorname{Tg}(m n x 1: G F P)$ larvae performed startle responses with stereotypic kinematic parameters, including a characteristic initial head turning angle of $\sim 130^{\circ}$ toward the right or left side (Fig. $4 N$ ). In each larva we spared the four anterior nerves, but transected the remaining 28 posterior spi- nal motor nerves innervating the right trunk and tail muscles (see Material and Methods for details). As before, we imaged these transected nerves and confirmed at $7 \mathrm{hpt}$ that the entire nerve portion distal to the transection site had fragmented, leaving behind only axonal debris (Fig. $4 P$, only nerves in hemisegments 5-10 shown), and at $48 \mathrm{hpt}$ confirmed that these nerves had reextended axons through the ventral myotome (Fig. $4 Q$, only nerves in hemisegments $5-10$ shown). At 3, 24 and $48 \mathrm{hpt}$ we assayed the ability of these larvae to perform rightward and leftward startle responses. At 3 and 24 hpt the head turning angles of rightward startle responses and overall swimming distances were dramatically reduced (Fig. $4 I, N, O)$. In contrast, by $48 \mathrm{hpt}$ these parameters had reached pre-lesion levels, suggesting that regrowing axons restored functionality to their muscle targets (Fig. $4 J, N, O, n=7$ larvae). Importantly, head turning angles of leftward startle responses at all time points were indistinguishable from those recorded before transection (Fig. $4 K-N, n=7$ larvae). Thus, following transection spinal motor neurons survive, reextend axons along their original trajectories, and restore functionality to their muscle targets.

\section{Macrophages arrive at the lesion site before axonal fragmentation}

Having established a reliable system for visualizing nerve degeneration and regeneration, we next examined macrophage behavior in response to nerve injury. Following insult axons fragment in a stereotyped manner leaving behind cellular and membranous debris, which is cleared by Schwann cell and macrophages (Waller, 1849; Lubińska, 1977; Beuche and Friede, 1984, 1986; for review, see Vargas and Barres, 2007). Macrophages have been reported to accumulate at the injured nerve only after fragmentation, and their recruitment is thought to depend on signals released from Schwann cells (Perry et al., 1987; Lunn et al., 1989; Stoll et al., 1989a,b; Monaco et al., 1992; Banner and Patterson, 1994; Avellino et al., 1995; Subang and Richardson, 1999; Hirata and Kawabuchi, 2002; Shamash et al., 2002; Tofaris et al., 2002; Vargas and Barres, 2007). Despite the significance of their proposed roles, when macrophages first arrive at the lesion and how they interact with injured nerves is not well documented, mainly due to the difficulties of continuously imaging inside live, intact vertebrate animals.

To monitor macrophage behavior in response to nerve transection in vivo and in real time we simultaneously imaged motor nerves using the $\mathrm{Tg}(X l a . T u b b: D s R e d)$ transgene, and spilpositive immune cells using the $T g($ spil:Gal4,UAS:EGFP) transgene (Peri and Nüsslein-Volhard, 2008). In zebrafish, spil (also known as $\mathrm{Pu} .1)$ promotes the differentiation of macrophages 


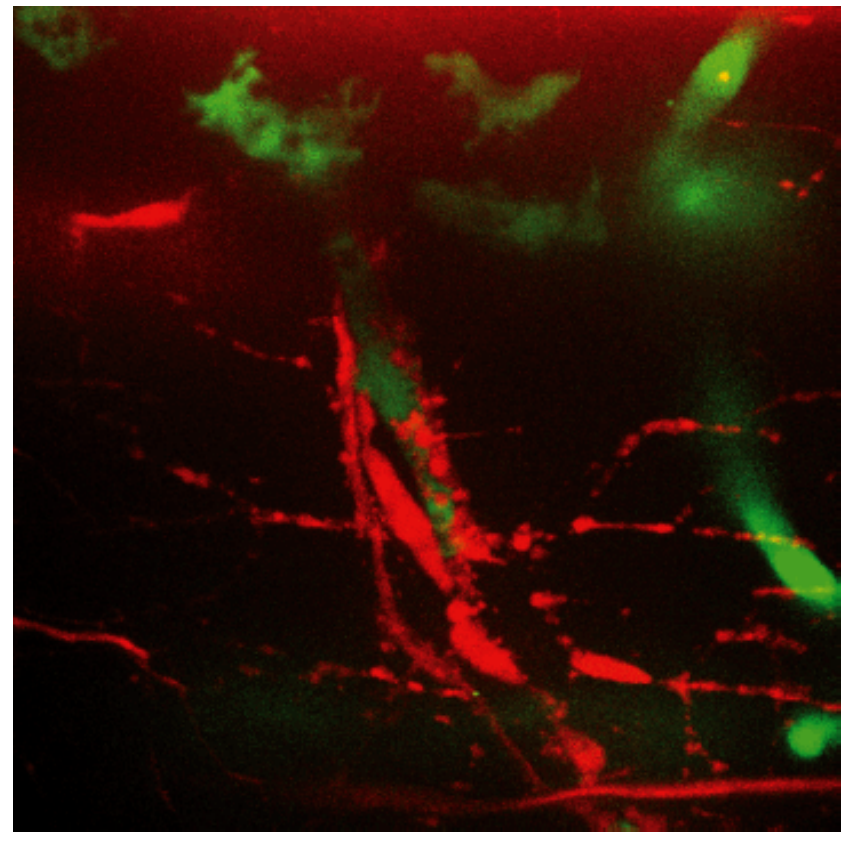

Movie 2. Time lapse imaging of 5 dpf larva documents macrophage recruitment to lesioned nerves and phagocytosis of axonal debris upon distal nerve fragmentation. Transgenic larva expresses cytoplasmic dsRed in all spinal motor neurons and GFP in macrophages ( $\mathrm{Tg}$ (X1a.Tubb: DsRed); Tg(spi1-Gal4,UAS-GFP)). Time lapse shows macrophages at the lesion site at $66 \mathrm{~min}$ postlesion, and macrophages infiltrating the distal nerve at 156 min post-lesion at the onset of nerve fragmentation. Following axonal fragmentation, macrophages phagocytose axonal debris. Frames are every $10 \mathrm{~min}$ for $\sim 7 \mathrm{~h}$.

from their myeloid precursors (for review, see Bennett et al., 2001; Rhodes et al., 2005), and the Tg(spi1:Gal4,UAS:EGFP) line has previously been shown to mark derivatives of the leukocyte linage, including microglia in the brain, as well as early macrophages in the trunk (Peri and Nüsslein-Volhard, 2008). Moreover, the appearance and behavior of spil:Gal4,UAS:EGFP-expressing cells that responded to nerve injury in the trunk (see below) were identical to those previously reported for zebrafish macrophages (Herbomel et al., 1999), and thus we will refer to these cells as macrophages. Before nerve transection the majority of macrophages were within blood vessels, and although a small number of spi1:Gal4,UAS:EGFP-expressing cells localized outside the vasculature, they were never observed along motor nerves (Fig. $5 A$ ). Analysis of 49 transected nerves revealed that in $>80 \%$ of cases macrophages left the vasculature and arrived at nerves within the first $120 \mathrm{~min}$ post-lesion, which is the earliest time point we observed the onset of axonal fragmentation (Fig. $5 B$, $C$; see also Movie 2). Moreover, in $69 \%$ of cases the first macrophages arrived within $60 \mathrm{~min}, \sim 60-120 \mathrm{~min}$ before the onset of axonal fragmentation (Table 1). Upon their arrival, macrophages preferentially localized to the distal nerve stump immediately adjacent to the lesion site, where some of these macrophages became stationary and assumed an ovoid morphology, though their membranes continued to ruffle (Fig. 5C). As soon as axons in the distal nerve began to fragment, macrophages infiltrated the fragmenting nerve and began to phagocytose axonal debris (Fig. 5D-F; see also Table 1). To confirm the identity of the GFP-positive cells in the $\mathrm{Tg}$ (spi1:Gal4,UAS:EGFP) line, we repeated these experiments in the $T g(m p e g 1: G F P)$ line (Ellett et al., 2011), which expresses GFP only in macrophages, and not in neutrophils. Following nerve lesion we find that in $62 \%$ of cases GFP-expressing macrophages arrived at lesioned motor nerves within the first hour of imaging ( $n=13$ motor nerves in 5 larvae),
Table 1. Quantification of macrophage recruitment to peripheral nerves following nerve transection or muscle lesion

\begin{tabular}{lllll}
\hline & Wild type & Wld $^{\text {s }}+$ nerves & sox $10^{-/-}$ & Muscle \\
\hline $\begin{array}{l}\text { \% of macrophages arriving within } 60 \text { min } \\
\text { post-lesion }\end{array}$ & $69(n=49)$ & $86(n=40)$ & $86(n=7)$ & $50(n=4)$ \\
$\begin{array}{l}\text { \% of macrophages arriving within } 120 \mathrm{~min} \\
\text { post-lesion }\end{array}$ & $86(n=49)$ & $100(n=40)$ & $86(n=7)$ & $100(n=4)$ \\
$\begin{array}{l}\text { Average number of macrophages/hemisegment } \\
\text { post-fragmentation }\end{array}$ & $3(n=36)$ & $3(n=14)$ & $3(n=7)$ & $\mathrm{ND}$ \\
$\begin{array}{l}\text { Median number of macrophages/hemisegment } \\
\text { post-fragmentation }\end{array}$ & $3(n=36)$ & $4(n=14)$ & $4(n=7)$ & $\mathrm{ND}$ \\
$\begin{array}{l}\text { Maximum number of macrophages/hemisegment } \\
\text { post-fragmentation }\end{array}$ & $8(n=36)$ & $6(n=14)$ & $5(n=7)$ & $\mathrm{ND}$ \\
\hline
\end{tabular}

Table 1 indicates the number and timing of macrophage recruitment to peripheral nerves following nerve transection in $5 \mathrm{dpf}$ wild-type larvae ( $\operatorname{Tg}\left(X 1 a\right.$.Tubb:DsRed); $\operatorname{Tg}\left(\right.$ spi1-Gal4,UAS-GFP)), Wld ${ }^{5}+$ larvae (Tg(mnx1:WId ${ }^{5}$-GFP);

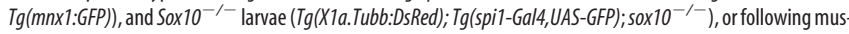
cle lesion in wild-type larvae. ND, Not determined.

and that their behavior was identical to the behavior of the spil: Gal4,UAS:EGFP-expressing cells in the $\mathrm{Tg}$ (spi1-Gal4,UAS-GFP) line (data not shown). Thus, macrophages arrive at the injury site long before nerve fragmentation, and with the onset of axonal fragmentation, macrophages enter the nerve and begin to phagocytose nerve debris.

We next asked whether potential damage caused during laser axotomy to neighboring tissue, such as muscle fibers, might influence macrophage recruitment. To address this we laser damaged a small area of a muscle fiber within $\sim 10-15$ $\mu \mathrm{m}$ of the nerve (same focal plane) without visibly damaging the nerve (Fig. 6A). Macrophages readily infiltrated the myotome (Fig. $6 B$ ), specifically targeted the damaged muscle fiber, and eventually left the area without invading the nerve (Fig. $6 C-F, n=4$ of 4 ; compared with Fig. 5 ). Thus, injury to nearby muscle cells does not trigger extensive cell contacts between macrophages and the nerve, suggesting that macrophage recruitment and invasion into the distal nerve following transection likely occurs in response to signals released by nerve constituents such as the motor axons, perineural glia, and/or Schwann cells.

\section{Macrophage behavior and recruitment to injured motor nerves is independent of Schwann cells and axonal Wld ${ }^{\mathrm{s}}$ expression}

Following nerve injury, macrophage recruitment and activation are thought to be triggered by reciprocal interactions between macrophages and Schwann cells (Banner and Patterson, 1994; Subang and Richardson, 1999; Shamash et al., 2002; Tofaris et al., 2002). However, injury-induced nerve degeneration in animals with a genetic ablation of all Schwann cells has not been examined. We therefore used sox $10^{-1-}$ (colorless) mutants, which lack all Schwann cells (Kelsh et al., 1996; Dutton et al., 2001). In these animals, motor axons develop without delay, and at $5 \mathrm{dpf}$ their motor nerves are morphologically indistinguishable from those in wild-type siblings (Fig. 7A). Following transection, degeneration of $\operatorname{Tg}(X 1 a$.Tubb:DsRed $)$; sox $10^{-1-}$ nerves proceeded with the same morphological and temporal parameters we had observed in wild-type siblings (Fig. $7 B-D$ ). Moreover, macrophages arrived at the nerve lesion site with timing and morphology similar to those seen in wild-type larvae (Fig. 7B; see also Table 1). Finally, macrophages also infiltrated the fragmenting distal nerve and phagocytosed axonal debris with the same time course observed in wild-type siblings (Fig. 7C,D). Thus, genetic ablation of Schwann cells demonstrates that macrophage recruitment and function at injured nerves can occur independently of Schwann cells. 

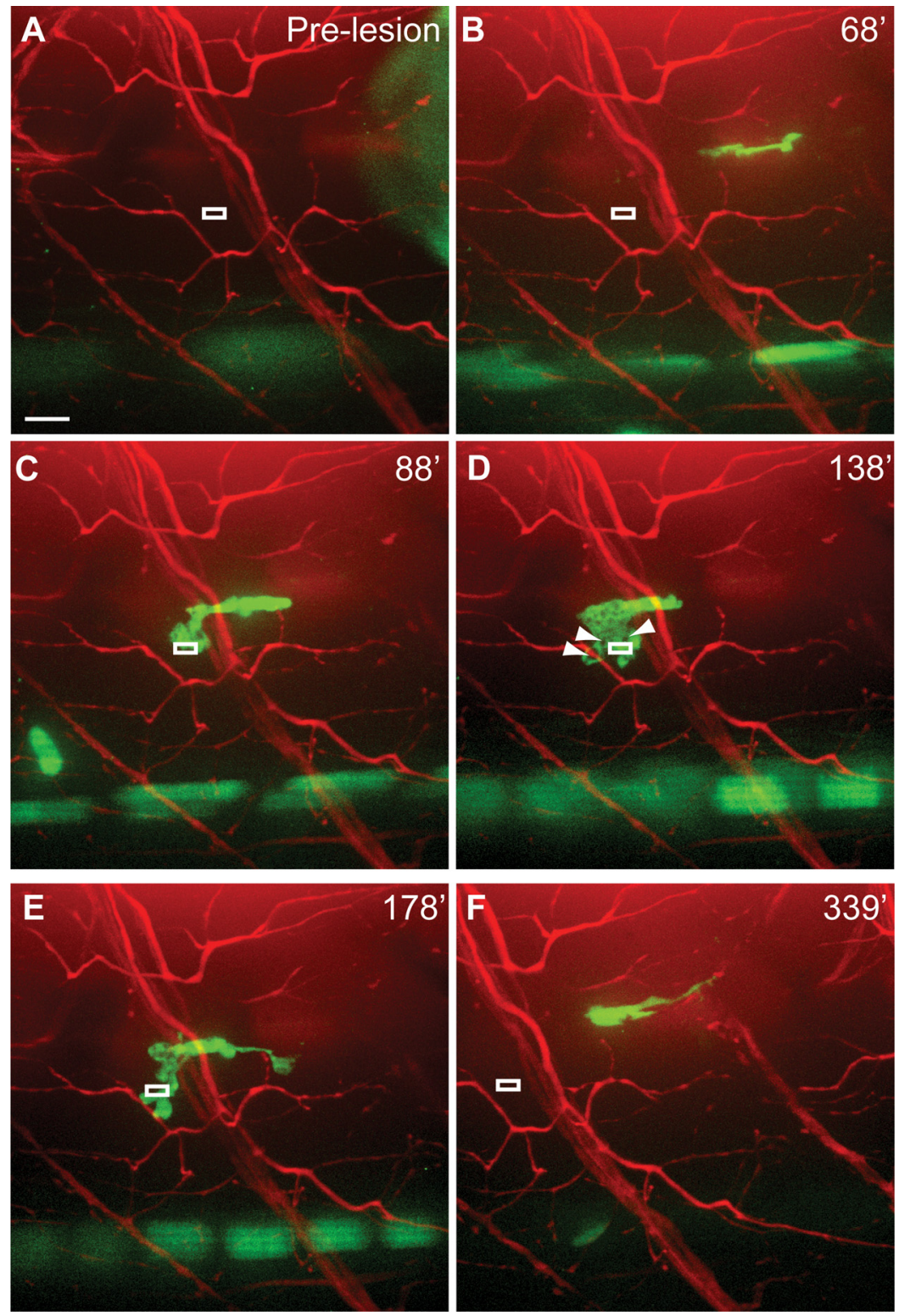

Figure 6. Recruitment and function of macrophages following muscle injury. $\boldsymbol{A}-\boldsymbol{C}$, Image sequence shows that upon lesion to nearby muscle tissue, macrophages migrate directly to the lesion site without investigating the nerve. $\boldsymbol{A}$, Pre-lesion image of Tg(X1a.Tubb:DsRed); $T g$ (spi1-Gal4;UAS-GFP) larva. White box indicates area of muscle lesion (muscle cells are unlabeled), at the same focal plane of the nerve. $\boldsymbol{B}$, A macrophage migrates directly to muscle lesion site $(\boldsymbol{C}) . \boldsymbol{D}, \boldsymbol{E}$, Macrophages remain at muscle lesion, and presumably phagocytose muscle cell debris (unlabeled), evidenced by vacuoles (arrowheads). $\boldsymbol{F}$, Eventually, macrophages exit the lesion site. Scale bar, $10 \mu \mathrm{m}$.

We next assessed whether and to what extent macrophage recruitment and behavior are modulated by processes intrinsic to injured axons. For this we monitored macrophage behavior after injury of Wld ${ }^{s}$-GFP-expressing nerves. Before nerve transection macrophages behaved indistinguishably from those in $T g(m n x 1: G F P)$ or $T g(X l a . T u b b: D s R e d)$ animals. Following nerve transection we found that macrophages were recruited to the lesion site of Wld ${ }^{\mathrm{s}}$-GFP-expressing nerves in similar numbers and within the same time frame when compared with wild-type nerves (Fig. 8B,C; see also Table 1). Despite the absence of axon fragmentation of Wld ${ }^{\mathrm{s}}$-GFP-expressing nerves, over the $10 \mathrm{~h}$ following transection macrophages remained in extensive contact with the distal nerve stump immediately adjacent to the lesion site (Fig. 8C-I). At irregular intervals during this time period macrophages located at the nerve stump elongated and extended a process ventrally along the distal nerve (Fig. $8 D-I, n=3$ of 15). This 'scanning' behavior, which we did not observe in wild-type nerves before the onset of axonal fragmentation, occurred without detectable signs of axonal fragmentation or phagocytosis (compare Fig. 5D,E with Fig. $8 D-I$ ). Thus, live imaging reveals that during Wallerian degeneration macrophage recruitment is insensitive to axonal Wld ${ }^{s}$-GFP, and describes a novel cellular behavior of macrophages when nerves fail to fragment.

\section{Discussion}

Wallerian degeneration is an early step toward functional nerve regeneration, and involves extensive cellular interactions between injured axons and multiple nonneuronal cells such as immune and glial cells. Early studies established that the environment generated by macrophages and Schwann cells is critical for successful nerve regeneration (Aguayo et al., 1981; David and Aguayo, 1981), and endpoint analysis of stained sections documented complex histological changes in Schwann cell appearance, myelin breakdown and macrophage influx following peripheral nerve injury (for review, see Martini et al., 2008). Albeit labor intensive and complex, in vivo imaging of nerve degeneration in murine models has been established, yet the focus has been primarily on changes in axons (Beirowski et al., 2004; Kerschensteiner et al., 2005). Thus, despite its importance, a minute-by-minute account of the cellular interactions between injured nerves and non-neuronal cells was lacking. Moreover, which of these cellular interactions are of functional significance is largely unknown.

We have taken advantage of the transparency of the zebrafish to precisely transect mature motor nerves and to image axonal destruction and the cellular response of macrophages in vivo and in real time. Overall, we find that nerve degeneration proceeds with the same morphological landmarks as those reported for Wallerian degeneration in mammals (Fig. 1; Waller, 1849; O'Daly and Imaeda, 1967; Lunn et al., 1989; George et al., 1995; Raff et al., 2002; Adalbert et al., 2005; Beirowski et al., 2005; Vargas and Barres, 2007; Martin et al., 2010). The lag time between injury and onset of axonal degeneration is known to vary significantly between vertebrate species (for review, see Vargas and Barres, 2007), and importantly, the lag time of 121-240 min we observed in zebrafish remained constant as larvae aged (6-14 dpf; data not shown), consistent with previous observations that motor nerves at $5 \mathrm{dpf}$ have established mature trajectories and connections (Westerfield and Eisen, 1988). Moreover, we find that expression of Wld ${ }^{s}$ in motor nerves effectively delays fragmentation, as previously reported in zebrafish sensory axons and in other species (Lunn et al., 1989; 
Wang et al., 2001; Raff et al., 2002; Araki et al., 2004; Adalbert et al., 2005; Hoopfer et al., 2006; MacDonald et al., 2006; Martin et al., 2010). In addition, we demonstrate that transected motor nerves reestablish functional connections with their muscle targets (Fig. 4). Together, these results validate zebrafish motor nerves as a model for functional nerve regeneration.

Our results characterize for the first time, and with unprecedented temporal and spatial resolution, the cellular interactions between injured nerves and immune cells. Importantly, these observations combined with genetic manipulations and cell type ablation lead to several new insights into the process of Wallerian degeneration. First, the spatiotemporal progression of axonal degeneration has historically been controversial, mainly due to the limitations of visualizing individual axons during this process. Earlier studies using fixed samples reported that axonal degeneration of dorsal root ganglion axons proceeds anterogradely at a rate of $\sim 3 \mathrm{~mm} / \mathrm{h}$ (George and Griffin, 1994a), and similar studies had correlated axonal diameter with the onset of nerve fragmentation (Lubińska, 1977, 1982), while more recent studies observed retrograde progression (Beirowski et al., 2005). By imaging individual axons within the degenerating nerve at $1 \mathrm{~min}$ intervals, our data show that axons and their branches fragment within less than a minute along their entire length (Fig. 2). Within a transected nerve, fragmentation of individual axons appears desynchronized and proceeds without apparent order, independent of axonal caliber (Fig. 2). While species differences concerning the rate of axonal fragmentation are well documented (for review, see Vargas and Barres, 2007), the data presented here reveals heterogeneity even among individual motor axons of similar length and caliber within a shared nerve, and to our knowledge provide the first minute-by-minute account of the destruction speed and synchrony of individual motor axons in a live, intact vertebrate animal.

Second, our live cell imaging demonstrates that macrophages arrive at the lesion site long before the onset of fragmentation, independent of Schwann cells. Early studies, based on fixed samples, reported that $24 \mathrm{~h}$ following sciatic nerve crush macrophage counts were not increased, and that macrophages arrived at the lesion site by the second day (Perry et al., 1987; Stoll et al., 1989a,b; George and Griffin, 1994a,b; for review, see Brück, 1997), when nerve fragmentation is well underway. Recent studies show that at $36 \mathrm{~h}$ post-lesion sciatic nerve fragmentation is accompanied by macrophages, yet the precise arrival of macrophages in relation to nerve fragmentation had not been established (Beirowski et al., 2004). We find that macrophages arrive at the lesion site 60-120 min before the onset of axonal fragmentation (Fig. 5). Following axonal fragmentation, macrophages infiltrate the distal portion of the injured nerve and phagocytose debris, as previously observed in mammalian systems (Perry et al., 1987; Stoll et al., 1989a). To determine the necessity of Schwann cells in signaling to macrophages during Wallerian degeneration we used sox $10^{-1-}$ mutants which lack Schwann cells (Kelsh et al., 1996; Dutton et al., 2001). Schwann cells are thought to release chemokine signals that recruit immune cells to the lesioned nerve (Banner and Patterson, 1994; Subang and Richardson, 1999; Shamash et al., 2002; Tofaris et al., 2002). For example, infusion of antibodies blocking MIP- $1 \alpha$ or macrophage chemoattractant protein-1 (MCP-1) function (Perrin et al., 2005), and genetic deletions of MCP-1 and its receptor CCR2, lead to reduced macrophage recruitment to the lesion site (Toews et al., 1998; Siebert et al., 2000). However, the role of Schwann cells on macrophage recruitment has not been determined in the complete absence of Schwann cells. We find that in the absence of Schwann cells motor axons develop normally, and upon lesion degenerate with the same morphology and kinematic parameters as observed in wild-type animals. Moreover, macrophages are recruited to the nerve lesion site with timing and numbers similar to those of wild-type animals, and upon axonal fragmentation also phagocytose debris (Fig. 7; see also Table 1), demonstrating that Schwann cells are dispensable for macrophage recruitment and function.

Last, our studies uncover a previously unknown behavior of macrophages when confronted with injured nerves in which fragmentation is delayed. Axonal expression of the $\mathrm{Wld}^{\mathrm{s}}$ protein not only delays nerve fragmentation, but is also thought to reduce macrophage recruitment to the lesioned nerve (Lunn et al., 1989). Live imaging reveals that macrophages are robustly recruited to injured Wld ${ }^{\text {s}}$-expressing nerves with timing and numbers similar to those of wild-type nerves (Fig. 8; see also Table 1). Although we cannot exclude the possibility that macrophages were attracted by damage to surrounding tissues or by axonal debris generated during laser transection, we observed macrophage recruitment in 15 of 15 transected nerves in which neither 

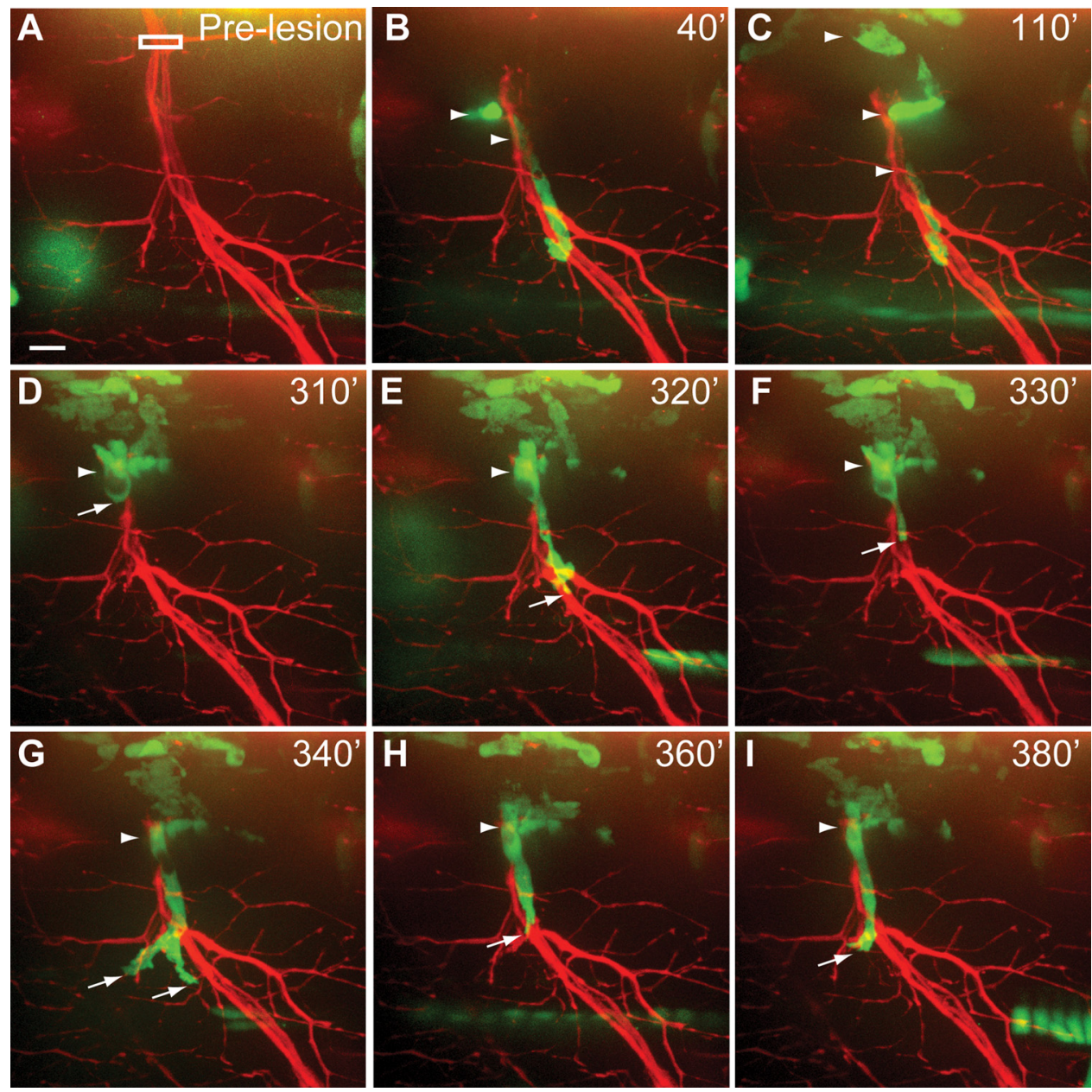

Figure 8. Macrophages are recruited to injured WId ${ }^{5}$-GFP-expressing nerves and display a novel behavior.A, Pre-lesion image in $T g(X 1 a . T u b b: D s R e d) ; T g(s p i 1-G a l 4, U A S-G F P) ; T g\left(m n x 1: W I d^{5}\right.$-GFP) larva. White box indicates area of laser axotomy. $B, C$, Macrophages (arrowheads) infiltrate the lesion site and accumulate at the lesioned nerve. D-I, During first $\sim 6.5 \mathrm{~h}$ following lesion, macrophages repeatedly extend and retract processes along the injured distal nerve. Scale bar, $10 \mu \mathrm{m}$.

axonal fragmentation nor phagocytosis of axonal material by macrophages was detectable (Fig. $5 E$ compared with Fig. 8C,G,I).

In the first $\sim 10 \mathrm{~h}$ following transection, macrophages maintain extensive contact with the Wld ${ }^{\mathrm{s}}$-expressing nerve stump, and exhibited a novel 'scanning' behavior, repeatedly extending and retracting a process along the distal nerve (Fig. 8). This behavior was distinct from macrophage behavior following wild-type axon fragmentation. While our observations are consistent with the idea that the prolonged presence of macrophages is insufficient to trigger axonal fragmentation, they also suggest that macrophage behavior is modulated by nerve integrity. While the absence of axonal fragmentation does not abrogate macrophage recruitment to an injured nerve, it alters 'on site' macrophage behavior. This is somewhat reminiscent of axonal injury in the CNS, where resident microglia migrate with some delay to the lesion site, but for unknown reasons exert limited phagocytic activity (Lawson et al., 1994; for review, see Barron, 1995; Cui et al., 2009). This low rate of phagocytic activity contributes to the slower Wallerian degeneration rate in the CNS, compared with the PNS, although the rates of axonal fragmentation in the PNS and the CNS are comparable (Stoll et al., 1989b; George and Griffin, 1994b), and thus cannot account for the difference in phagocytic behavior. In contrast, the 'scanning' behavior we observe is only exhibited in the absence of nerve fragmentation. Such behavioral plasticity exhibited by leukocytes has previously not been reported and strongly suggests the existence of multiple, possibly independent signals regulating macrophage activity. A first signal attracts leukocytes to the injured nerve, while subsequent signal(s) initiate leukocyte invasion and phagocytosis of the distal nerve. While future studies are required to identify these signals, our results demonstrate the need to visualize in real time and at the functional level the complex interactions between the cell types involved in nerve degeneration and regeneration to define the molecular mechanisms that trigger and mediate these processes.

\section{References}

Adalbert R, Gillingwater TH, Haley JE, Bridge K, Beirowski B, Berek L, Wagner D, Grumme D, Thomson D, Celik A, Addicks K, Ribchester RR, Coleman MP (2005) A rat model of slow Wallerian degeneration (WldS) with improved preservation of neuromuscular synapses. Eur J Neurosci 21:271-277.

Aguayo AJ, David S, Bray GM (1981) Influences of the glial environment on the elongation of axons after injury: transplantation studies in adult rodents. J Exp Biol 95:231-240.

Araki T, Sasaki Y, Milbrandt J (2004) Increased nuclear NAD biosynthesis and SIRT1 activation prevent axonal degeneration. Science 305:1010-1013.

Avellino AM, Hart D, Dailey AT, MacKinnon M, Ellegala D, Kliot M (1995) Differential macrophage responses in the peripheral and central nervous system during wallerian degeneration of axons. Exp Neurol 136:183-198.

Banner LR, Patterson PH (1994) Major changes in the expression of the mRNAs for cholinergic differentiation factor/leukemia inhibitory factor 
and its receptor after injury to adult peripheral nerves and ganglia. Proc Natl Acad Sci U S A 91:7109-7113.

Barron KD (1995) The microglial cell. A historical review. J Neurol Sci 134 [Suppl]:57-68.

Beirowski B, Berek L, Adalbert R, Wagner D, Grumme DS, Addicks K, Ribchester RR, Coleman MP (2004) Quantitative and qualitative analysis of Wallerian degeneration using restricted axonal labelling in YFP-H mice. J Neurosci Methods 134:23-35.

Beirowski B, Adalbert R, Wagner D, Grumme DS, Addicks K, Ribchester RR, Coleman MP (2005) The progressive nature of Wallerian degeneration in wild-type and slow Wallerian degeneration (WldS) nerves. BMC Neuroscience 6:6.

Bennett CM, Kanki JP, Rhodes J, Liu TX, Paw BH, Kieran MW, Langenau DM, Delahaye-Brown A, Zon LI, Fleming MD, Look AT (2001) Myelopoiesis in the zebrafish, Danio rerio. Blood 98:643-651.

Beuche W, Friede RL (1984) The role of non-resident cells in Wallerian degeneration. J Neurocytol 13:767-796.

Beuche W, Friede RL (1986) Myelin phagocytosis in Wallerian degeneration of peripheral nerves depends on silica-sensitive, bg/bg-negative and Fc-positive monocytes. Brain Res 378:97-106.

Bhatt DH, Otto SJ, Depoister B, Fetcho JR (2004) Cyclic AMP-induced repair of zebrafish spinal circuits. Science 305:254-258.

Bisby MA, Chen S (1990) Delayed wallerian degeneration in sciatic nerves of C57BL/Ola mice is associated with impaired regeneration of sensory axons. Brain Res 530:117-120.

Brown MC, Lunn ER, Perry VH (1992) Consequences of slow Wallerian degeneration for regenerating motor and sensory axons. J Neurobiol 23:521-536.

Brück W (1997) The role of macrophages in Wallerian degeneration. Brain Pathol 7:741-752.

Burgess HA, Granato M (2007) Modulation of locomotor activity in larval zebrafish during light adaptation. J Exp Biol 210:2526-2539.

Burgess HA, Johnson SL, Granato M (2009) Unidirectional startle responses and disrupted left-right co-ordination of motor behaviors in robo3 mutant zebrafish. Genes Brain Behav 8:500-511.

Chen S, Bisby MA (1993a) Impaired motor axon regeneration in the C57BL/Ola mouse. J Comp Neurol 333:449-454.

Chen S, Bisby MA (1993b) Long-term consequences of impaired regeneration on facial motoneurons in the C57BL/Ola mouse. J Comp Neurol 335:576-585.

Coleman MP, Conforti L, Buckmaster EA, Tarlton A, Ewing RM, Brown MC, Lyon MF, Perry VH (1998) An 85-kb tandem triplication in the slow Wallerian degeneration (Wlds) mouse. Proc Natl Acad Sci U S A 95:9985-9990.

Conforti L, Tarlton A, Mack TG, Mi W, Buckmaster EA, Wagner D, Perry VH, Coleman MP (2000) A Ufd2/D4Colele chimeric protein and overexpression of Rbp7 in the slow Wallerian degeneration (WldS) mouse. Proc Natl Acad Sci U S A 97:11377-11382.

Cui Q, Yin Y, Benowitz LI (2009) The role of macrophages in optic nerve regeneration. Neuroscience 158:1039-1048.

David S, Aguayo AJ (1981) Axonal elongation into peripheral nervous system "bridges" after central nervous system injury in adult rats. Science 214:931-933.

Downes GB, Waterbury JA, Granato M (2002) Rapid in vivo labeling of identified zebrafish neurons. Genesis 34:196-202.

Dutton KA, Pauliny A, Lopes SS, Elworthy S, Carney TJ, Rauch J, Geisler R, Haffter P, Kelsh RN (2001) Zebrafish colourless encodes sox10 and specifies non-ectomesenchymal neural crest fates. Development 128:4113-4125.

Eaton RC, Hackett JT (1984) The role of the Mauthner cell in fast-starts involving escape in teleost fish. New York: Plenum.

Ellett F, Pase L, Hayman JW, Andrianopoulos A, Lieschke GJ (2011) mpeg1 promoter transgenes direct macrophage-lineage expression in zebrafish. Blood 117:e49-e56.

Feng Y, Yan T, Zheng J, Ge X, Mu Y, Zhang Y, Wu D, Du JL, Zhai Q (2010) Overexpression of Wld(S) or Nmnat2 in Mauthner cells by single-cell electroporation delays axon degeneration in live zebrafish. J Neurosci Res 88:3319-3327.

Flanagan-Steet H, Fox MA, Meyer D, Sanes JR (2005) Neuromuscular synapses can form in vivo by incorporation of initially aneural postsynaptic specializations. Development 132:4471-4481.
Garbay B, Heape AM, Sargueil F, Cassagne C (2000) Myelin synthesis in the peripheral nervous system. Prog Neurobiol 61:267-304.

George EB, Glass JD, Griffin JW (1995) Axotomy-induced axonal degeneration is mediated by calcium influx through ion-specific channels. J Neurosci 15:6445-6452.

George R, Griffin JW (1994a) Delayed macrophage responses and myelin clearance during Wallerian degeneration in the central nervous system: the dorsal radiculotomy model. Exp Neurol 129:225-236.

George R, Griffin JW (1994b) The proximo-distal spread of axonal degeneration in the dorsal columns of the rat. J Neurocytol 23:657-667.

Hahn AF, Chang Y, Webster HD (1987) Development of myelinated nerve fibers in the sixth cranial nerve of the rat: a quantitative electron microscope study. J Comp Neurol 260:491-500.

Hartley JL, Temple GF, Brasch MA (2000) DNA cloning using in vitro sitespecific recombination. Genome Res 10:1788-1795.

Herbomel P, Thisse B, Thisse C (1999) Ontogeny and behaviour of early macrophages in the zebrafish embryo. Development 126:3735-3745.

Hirata K, Kawabuchi M (2002) Myelin phagocytosis by macrophages and nonmacrophages during Wallerian degeneration. Microsc Res Tech 57:541-547.

Hirata K, Mitoma H, Ueno N, He JW, Kawabuchi M (1999) Differential response of macrophage subpopulations to myelin degradation in the injured rat sciatic nerve. J Neurocytol 28:685-695.

Holtzman E, Novikoff AB (1965) Lysomes in the rat sciatic nerve following crush. J Cell Biol 27:651-669.

Hoopfer ED, McLaughlin T, Watts RJ, Schuldiner O, O'Leary DD, Luo L (2006) Wlds protection distinguishes axon degeneration following injury from naturally occurring developmental pruning. Neuron 50:883-895.

Kelsh RN, Brand M, Jiang YJ, Heisenberg CP, Lin S, Haffter P, Odenthal J, Mullins MC, van Eeden FJ, Furutani-Seiki M, Granato M, Hammerschmidt M, Kane DA, Warga RM, Beuchle D, Vogelsang L, NüssleinVolhard C (1996) Zebrafish pigmentation mutations and the processes of neural crest development. Development 123:369-389.

Kerschensteiner M, Schwab ME, Lichtman JW, Misgeld T (2005) In vivo imaging of axonal degeneration and regeneration in the injured spinal cord. Nat Med 11:572-577.

Kimmel CB, Patterson J, Kimmel RO (1974) The development and behavioral characteristics of the startle response in the zebra fish. Dev Psychobiol 7:47-60.

Lawson LJ, Frost L, Risbridger J, Fearn S, Perry VH (1994) Quantification of the mononuclear phagocyte response to Wallerian degeneration of the optic nerve. J Neurocytol 23:729-744.

Liu DW, Westerfield M (1988) Function of identified motoneurones and co-ordination of primary and secondary motor systems during zebra fish swimming. J Physiol 403:73-89.

Liu KS, Fetcho JR (1999) Laser ablations reveal functional relationships of segmental hindbrain neurons in zebrafish. Neuron 23:325-335.

Lubińska L (1977) Early course of Wallerian degeneration in myelinated fibres of the rat phrenic nerve. Brain Res 130:47-63.

Lubińska L (1982) Patterns of Wallerian degeneration of myelinated fibres in short and long peripheral stumps and in isolated segments of rat phrenic nerve. Interpretation of the role of axoplasmic flow of the trophic factor. Brain Res 233:227-240.

Lunn ER, Perry VH, Brown MC, Rosen H, Gordon S (1989) Absence of Wallerian degeneration does not hinder regeneration in peripheral nerve. Eur J Neurosci 1:27-33.

MacDonald JM, Beach MG, Porpiglia E, Sheehan AE, Watts RJ, Freeman MR (2006) The Drosophila cell corpse engulfment receptor Draper mediates glial clearance of severed axons. Neuron 50:869-881.

Martin SM, O’Brien GS, Portera-Cailliau C, Sagasti A (2010) Wallerian degeneration of zebrafish trigeminal axons in the skin is required for regeneration and developmental pruning. Development 137:3985-3994.

Martini R, Fischer S, López-Vales R, David S (2008) Interactions between Schwann cells and macrophages in injury and inherited demyelinating disease. Glia 56:1566-1577.

Monaco S, Gehrmann J, Raivich G, Kreutzberg GW (1992) MHC-positive, ramified macrophages in the normal and injured rat peripheral nervous system. J Neurocytol 21:623-634.

Mullins MC, Hammerschmidt M, Haffter P, Nüsslein-Volhard C (1994) Large-scale mutagenesis in the zebrafish: in search of genes controlling development in a vertebrate. Curr Biol 4:189-202. 
Myers PZ (1985) Spinal motoneurons of the larval zebrafish. J Comp Neurol 236:555-561.

Myers PZ, Eisen JS, Westerfield M (1986) Development and axonal outgrowth of identified motoneurons in the zebrafish. J Neurosci 6:2278-2289.

O’Brien GS, Martin SM, Söllner C, Wright GJ, Becker CG, PorteraCailliau C, Sagasti A (2009) Developmentally regulated impediments to skin reinnervation by injured peripheral sensory axon terminals. Curr Biol 19:2086-2090.

O'Daly JA, Imaeda T (1967) Electron microscopic study of Wallerian degeneration in cutaneous nerves caused by mechanical injury. Lab Invest 17:744-766.

Peri F, Nüsslein-Volhard C (2008) Live imaging of neuronal degradation by microglia reveals a role for v0-ATPase al in phagosomal fusion in vivo. Cell 133:916-927.

Perrin FE, Lacroix S, Avilés-Trigueros M, David S (2005) Involvement of monocyte chemoattractant protein-1, macrophage inflammatory protein-1alpha and interleukin-1beta in Wallerian degeneration. Brain 128:854-866.

Perry VH, Brown MC (1992) Role of macrophages in peripheral nerve degeneration and repair. Bioessays 14:401-406.

Perry VH, Brown MC, Gordon S (1987) The macrophage response to central and peripheral nerve injury. A possible role for macrophages in regeneration. J Exp Med 165:1218-1223.

Perry VH, Lunn ER, Brown MC, Cahusac S, Gordon S (1990) Evidence that the rate of Wallerian degeneration is controlled by a single autosomal dominant gene. Eur J Neurosci 2:408-413.

Peters A, Muir AR (1959) The relationship between axons and Schwann cells during development of peripheral nerves in the rat. Q J Exp Physiol Cogn Med Sci 44:117-130.

Raff MC, Whitmore AV, Finn JT (2002) Axonal self-destruction and neurodegeneration. Science 296:868-871.

Reimer MM, Kuscha V, Wyatt C, Sörensen I, Frank RE, Knüwer M, Becker T, Becker CG (2009) Sonic hedgehog is a polarized signal for motor neuron regeneration in adult zebrafish. J Neurosci 29:15073-15082.

Rhodes J, Hagen A, Hsu K, Deng M, Liu TX, Look AT, Kanki JP (2005) Interplay of pu. 1 and gatal determines myelo-erythroid progenitor cell fate in zebrafish. Dev Cell 8:97-108.

Schlaepfer WW, Myers FK (1973) Relationship of myelin internode elongation and growth in the rat sural nerve. J Comp Neurol 147:255-266.

Shamash S, Reichert F, Rotshenker S (2002) The cytokine network of Wallerian degeneration: tumor necrosis factor-alpha, interleukin-1alpha, and interleukin-1beta. J Neurosci 22:3052-3060.

Siebert H, Sachse A, Kuziel WA, Maeda N, Brück W (2000) The chemokine receptor CCR2 is involved in macrophage recruitment to the injured peripheral nervous system. J Neuroimmunol 110:177-185.
Stoll G, Trapp BD, Griffin JW (1989a) Macrophage function during Wallerian degeneration of rat optic nerve: clearance of degenerating myelin and Ia expression. J Neurosci 9:2327-2335.

Stoll G, Griffin JW, Li CY, Trapp BD (1989b) Wallerian degeneration in the peripheral nervous system: participation of both Schwann cells and macrophages in myelin degradation. J Neurocytol 18:671-683.

Subang MC, Richardson PM (1999) Tumor necrosis factor-alpha induces monocyte chemoattractant protein-1 mRNA in a Schwann cell line. Ann N Y Acad Sci 883:523-525.

Thermes V, Grabher C, Ristoratore F, Bourrat F, Choulika A, Wittbrodt J, Joly JS (2002) I-SceI meganuclease mediates highly efficient transgenesis in fish. Mech Dev 118:91-98.

Toews AD, Barrett C, Morell P (1998) Monocyte chemoattractant protein 1 is responsible for macrophage recruitment following injury to sciatic nerve. J Neurosci Res 53:260-267.

Tofaris GK, Patterson PH, Jessen KR, Mirsky R (2002) Denervated Schwann cells attract macrophages by secretion of leukemia inhibitory factor (LIF) and monocyte chemoattractant protein- 1 in a process regulated by interleukin-6 and LIF. J Neurosci 22:6696-6703.

van Raamsdonk W, Maslam S, de Jong DH, Smit-Onel MJ, Velzing E (1998) Long term effects of spinal cord transection in zebrafish: swimming performances, and metabolic properties of the neuromuscular system. Acta Histochem 100:117-131.

Vargas ME, Barres BA (2007) Why is Wallerian degeneration in the CNS so slow? Annu Rev Neurosci 30:153-179.

Waller A (1849) Experiments on the section of the glossopharyngeal and hypoglossal nerves of the frog, and observations of the alterations produced thereby in the structure of their primitive fibres. Philos Trans R Soc Lond 140:423-429.

Wang MS, Fang G, Culver DG, Davis AA, Rich MM, Glass JD (2001) The WldS protein protects against axonal degeneration: a model of gene therapy for peripheral neuropathy. Ann Neurol 50:773-779.

Westerfield M, Eisen JS (1988) Neuromuscular specificity: pathfinding by identified motor growth cones in a vertebrate embryo. Trends Neurosci 11:18-22.

Westerfield M, McMurray JV, Eisen JS (1986) Identified motoneurons and their innervation of axial muscles in the zebrafish. J Neurosci 6:2267-2277.

Wyatt C, Ebert A, Reimer MM, Rasband K, Hardy M, Chien CB, Becker T, Becker CG (2010) Analysis of the astray/robo2 zebrafish mutant reveals that degenerating tracts do not provide strong guidance cues for regenerating optic axons. J Neurosci 30:13838-13849.

Zhang J, Lefebvre JL, Zhao S, Granato M (2004) Zebrafish unplugged reveals a role for muscle-specific kinase homologs in axonal pathway choice. Nat Neurosci 7:1303-1309. 